\title{
Systemic exposure of the parent drug oxaliplatin during hyperthermic intraperitoneal perfusion
}

\author{
H. Mahteme • I. Wallin • B. Glimelius • L. PåhIman • \\ H. Ehrsson
}

Received: 27 March 2008 / Accepted: 20 May 2008 / Published online: 18 June 2008

(C) The Author(s) 2008

\begin{abstract}
Objective To evaluate the perfusate and systemic kinetics of oxaliplatin during hyperthermic intraperitoneal chemotherapy (HIPEC) using a selective analytical technique. Methods HIPEC was carried out in eight patients by the open abdomen coliseum technique for $30 \mathrm{~min}$ at $41.5-43^{\circ} \mathrm{C}$ with an average of $427 \mathrm{mg} / \mathrm{m}^{2}$ of oxaliplatin in $5 \%$ dextrose solution. Blood and perfusate samples were collected during the perfusion. Additional blood samples were taken up to $2 \mathrm{~h}$ after the end of perfusion. The analysis was performed by liquid chromatography and post-column derivatization with $\mathrm{N}, \mathrm{N}$-diethyldithiocarbamate using microwave heating.

Results The mean elimination half-life of oxaliplatin in the perfusate was $29.5 \mathrm{~min}$ (range 21.1-41.2 $\mathrm{min}$ ) and in the peripheral circulation $24.7 \mathrm{~min}$ (range 21.7-27.7 min). The ratio of the areas under the time concentration curve in perfusate and blood was $12.8 \pm 2.9$.
\end{abstract}

H. Mahteme $\cdot$ L. Påhlman

Department of Surgical Sciences, Section of Surgery,

Akademiska Sjukhuset,

Uppsala, Sweden

\section{B. Glimelius}

Department of Oncology, Radiology and Clinical Immunology,

Akademiska Sjukhuset,

Uppsala, Sweden

I. Wallin $\cdot$ H. Ehrsson $(\bowtie)$

Karolinska Pharmacy, Karolinska University Hospital,

SE 17176 Stockholm, Sweden

e-mail: hans.ehrsson@apoteket.se

B. Glimelius $\cdot$ H. Ehrsson

Department of Oncology-Pathology, Karolinska Institutet,

Stockholm, Sweden
Conclusion The systemic exposure of oxaliplatin measured after HIPEC using a selective analytical technique is considerably lower than previously reported results obtained by atomic absorption spectroscopy.

Keywords Intraperitoneal chemotherapy · Hyperthermia · Pharmacokinetics · Oxaliplatin

\section{Introduction}

Peritoneal carcinomatosis (PC) from colorectal cancer implies a poor prognosis [1-3]. However, in selected patients, peritonectomy followed by oxaliplatin-based hyperthermic intraperitoneal chemotherapy (HIPEC) has in some cases been curative and has in the majority of cases prolonged survival $[4,5]$. Oxaliplatin, a third-generation antineoplastic platinum complex, is currently used in the treatment of advanced colorectal cancer. Previous kinetic studies of oxaliplatin during HIPEC have been based on the use of atomic absorption spectroscopy (AAS), an unselective analytical technique measuring the total platinum content in plasma ultrafiltrate or plasma [6,7]. This method will codetermine oxaliplatin and platinum $(\mathrm{Pt})$-containing cytotoxic and biologically inactive biotransformation products.

A method for quantitative determination of the free fraction of intact oxaliplatin in blood ultrafiltrate has been developed [8] and applied to pharmacokinetic studies in humans [9-11]. The results establish that oxaliplatin has a drastically shorter terminal elimination half-life than was suggested based on results obtained by AAS, $15 \mathrm{~min}$ vs. $32-47 \mathrm{~h}$ respectively [12].

The aim of this study was to analyse the free fraction of intact oxaliplatin in peritoneal perfusate and blood after 
oxaliplatin administration in a HIPEC setting, using a selective analytical technique.

\section{Methods}

Patients

Eight patients with $\mathrm{PC}$ who underwent peritonectomy and oxaliplatin-based HIPEC at the Uppsala University Hospital were included. The regional ethics committees approved the study and informed consent was obtained from each patient.

There were five women and three men of mean age 56 (range 39-64) years (Table 1). The primary tumour types were colorectal adenocarcinoma (CRC) (4), recurrent epithelial ovarian cancer (3) and gastric adenocarcinoma (1). The eligibility requirements for treatment were as follows: histologically confirmed diagnosis of PC; no distant metastases; adequate renal, haematopoietic and liver functions; and WHO performance status $\leq 2$. However, one patient with CRC had associated liver metastases treated by right-sided hemihepatectomy during the same procedure.

\section{HIPEC}

Oxaliplatin was given using the coliseum technique as described by Sugerbaker [13]. Briefly, a Tenckhoff inflow catheter is placed centrally in the abdomen and four outflow catheters are inserted through separate stab incisions in the abdominal wall. Both the inflow and outflow catheters are connected to a perfusion pump and heat exchanger. The skin of the abdomen is attached to a retractor ring, and the abdominal cavity is covered with a plastic sheet with a small opening in the centre allowing entrance for the surgeon's hands to stir the abdominal contents resulting in a better exposure of the intraabdominal surfaces and a more uniform distribution of drug and heat. The dose of oxaliplatin $\left(460 \mathrm{mg} / \mathrm{m}^{2}\right)$ was planned according to the findings of Elias [6]. However, since all patients had received a preoperative neo-adjuvant chemotherapy prior to peritonectomy and HIPEC, the patients received a reduced dose (mean $427 \mathrm{mg} / \mathrm{m}^{2}$ ) and also concomitant iv 5 -FU $\left(500 \mathrm{mg} / \mathrm{m}^{2}\right)$ plus iv calcium levofolinate $\left(30 \mathrm{mg} / \mathrm{m}^{2}\right)$. The body surface area determined the volume of the carrier solution and electrolyte-free glucose $(50 \mathrm{mg} / \mathrm{ml})$ was used for oxaliplatin perfusion. The duration of the perfusion was $30 \mathrm{~min}$ as described by Elias [6]. Prior to the start of perfusion, the patients were cooled to $35^{\circ} \mathrm{C}$ with a cooling blanket. The intraabdominal temperature during perfusion ranged from 41.5 to $43^{\circ} \mathrm{C}$. In all patients, four intraabdominal drains were left in place after surgery.

\section{Perfusate and blood sampling}

Perfusate and arterial blood $(2 \mathrm{ml})$ were drawn before HIPEC and at 2, 5, 10, 15, 20 and 30 min during the perfusion. Additional peripheral blood was collected at 1 , $15,30,60,90$ and $120 \mathrm{~min}$ after the end of the perfusion.

\section{Oxaliplatin analysis}

Handling of the blood samples and liquid chromatographic analysis were performed according to a procedure described previously [8]. Briefly, blood was collected in prechilled Vacutainer tubes, stored on ice and dispensed in prechilled Centrisart tubes. The samples were ultrafiltrated centripetally at $4^{\circ} \mathrm{C}$ within $30 \mathrm{~min}$ from sampling $(4,000 \times g$, $20 \mathrm{~min}$ ). The ultrafiltrates were promptly frozen on dry ice stored at $-80^{\circ} \mathrm{C}$ and analysed within 3 weeks. Oxaliplatin was separated on a Hypercarb $\mathrm{S}$ column using a mobile phase of methanol/succinic acid buffer $0.25 \mathrm{M}, \mathrm{pH}$

Table 1 Patient characteristics and oxaliplatin perfusion

\begin{tabular}{|c|c|c|c|c|c|c|c|c|c|c|}
\hline Patient & $\begin{array}{l}\text { Age } \\
\text { (years) }\end{array}$ & Gender & $\begin{array}{l}\text { Weight } \\
(\mathrm{kg})\end{array}$ & $\begin{array}{l}\mathrm{SA} \\
\left(\mathrm{m}^{2}\right)\end{array}$ & $\begin{array}{l}\text { BMI } \\
\left(\mathrm{kg} / \mathrm{m}^{2}\right)\end{array}$ & $\begin{array}{l}\text { Primary } \\
\text { tumour site }\end{array}$ & $\begin{array}{l}\text { EVF during } \\
\text { sampling }\end{array}$ & $\begin{array}{l}\text { Dose } \\
(\mathrm{mg})\end{array}$ & $\begin{array}{l}\text { Dose } \\
\left(\mathrm{mg} / \mathrm{m}^{2}\right)\end{array}$ & $\begin{array}{l}\text { Volume } \\
\text { perfusate (1) }\end{array}$ \\
\hline 1 & 57 & M & 69 & 1.84 & 22.3 & CRC & 25 & 840 & 457 & 3.2 \\
\hline 2 & 64 & $\mathrm{~F}$ & 68 & 1.72 & 26.2 & Ovarian & 25 & 780 & 453 & 3.2 \\
\hline 3 & 54 & $\mathrm{~F}$ & 86 & 2.06 & 26.5 & Ovarian & 26 & 920 & 447 & 4.2 \\
\hline 4 & 56 & M & 80 & 2.02 & 23.9 & $\mathrm{CRC}$ & 40 & 925 & 459 & 3.2 \\
\hline 5 & 59 & $\mathrm{~F}$ & 55 & 1.58 & 21.0 & $\mathrm{CRC}$ & 32 & 615 & 389 & 2.1 \\
\hline 6 & 57 & $\mathrm{~F}$ & 65 & 1.73 & 23.3 & $\mathrm{CRC}$ & 30 & 690 & 399 & 3.1 \\
\hline 7 & 59 & $\mathrm{~F}$ & 60 & 1.72 & 20.0 & Ovarian & 27 & 700 & 407 & 4.1 \\
\hline 8 & 39 & M & 84 & 1.96 & 28.7 & Gastric & 27 & 800 & 408 & 2.7 \\
\hline Mean \pm SD & $56 \pm 7$ & & $71 \pm 11$ & $1.83 \pm 0.17$ & $24.0 \pm 3.0$ & & $29 \pm 5$ & $784 \pm 111$ & $427 \pm 29$ & $3.2 \pm 0.7$ \\
\hline
\end{tabular}

$S A$ Surface area, $B M I$ body mass index, $E V F$ erythrocyte volume fraction, $C R C$ colorectal adenocarcinoma 
$7.0(9 / 1 \mathrm{v} / \mathrm{v})$, with a flow rate of $0.5 \mathrm{ml} / \mathrm{min}$. The postcolumn derivatization was performed by mixing the mobile phase with $2.7 \mathrm{mM} \mathrm{N}$,N-diethyldithiocarbamate in methanol (flow: $0.17 \mathrm{ml} / \mathrm{min}$ ) followed by microwave heating (SmithCreator) in Teflon tubing $(2 \mathrm{~m})$. The quantification was carried out by photometric detection at $344 \mathrm{~nm}$.

Standard curves in blood were prepared by adding oxaliplatin to blood with the same EFV as the patient to be analysed. The standards $(0.1-25 \mu \mathrm{M})$ were ultrafiltrated and treated in the same way as the patient samples.

Perfusate samples were treated as blood, and standards were prepared in distilled water. Before LC analysis, the perfusate samples were diluted 100 times with water.

Samples from blood and perfusate were always run in parallel with the corresponding standards.

In vitro degradation of oxaliplatin in perfusate from treated patients

A portion of the perfusate samples $(n=6)$ from each patient were mixed, promptly placed on dry ice and stored at $-80^{\circ} \mathrm{C}$ for no more than 1 week until the study was performed. The degradation rate of oxaliplatin in each perfusate mixture was determined at $43^{\circ} \mathrm{C}$. The analysis was carried out as described above. The degradation rate constants were used to correct for the chemical degradation in the perfusate when calculating the dose of oxaliplatin absorbed.

\section{Pharmacokinetic and statistical evaluation}

The area under the blood ultrafiltrate (UF) concentration (AUC) time curves was determined by the trapezoidal rule. Time for infusion of saline to rinse the peritoneal cavity was considered to be the stop time of perfusion. The terminal elimination half-lives in blood-UF were evaluated from $15 \mathrm{~min}$ after perfusion stop until the last sampling time.

The area under the perfusion time curves was integrated under the fitted curve, extrapolated to time zero and perfusion stop time.

The correlation between body mass index (BMI) and percent oxaliplatin absorbed was evaluated by Spearman rank correlation. Mann-Whitney test (two-tailed) was used when comparing blood ultrafiltrate half-life and clearance during HIPEC with previous data after iv administration [11]. The iv group consisted of eight patients with similar gender distribution, age and weight who received $130 \mathrm{mg} / \mathrm{m}^{2}$ of oxaliplatin over $30 \mathrm{~min}$. For all calculations and statistical analysis Prism for Windows, version 3.0 (GraphPad Software, San Diego, CA, USA) was used. $P$ values $<0.05$ were taken as significant.

\section{Results}

Surgical treatment

The peritonectomy was performed as described by Sugerbaker [14]. The extent of tumour load and completeness of surgical resection were immediately recorded postoperatively using the Peritoneal Cancer Index (PCI) and Completeness of Cytoreduction Score (CC) respectively [15]. The PCI categorizes lesion size scores in 13 different regions of the abdomen: $0=$ no visible tumour, $1=$ tumour up to $0.5 \mathrm{~cm}, 2=$ tumour up to $5 \mathrm{~cm}$ and $3=$ tumour $>5 \mathrm{~cm}$. The maximum PCI is 39 . The CC score is based on the size of tumour remnants after cytoreduction: $0=$ no peritoneal seeding visible, $1=$ nodules up to $2.5 \mathrm{~mm}$, $2=$ nodules up to $2.5 \mathrm{~cm}$ and $3=$ nodules $>2.5 \mathrm{~cm}$.

The mean operating time was $9.4 \pm 1.9 \mathrm{~h}$ with a mean blood loss of $763 \pm 302 \mathrm{ml}$ (range 400-1,200 ml). Mean PCI was 21 (range 6-37). Complete cytoreduction (CC-0) was achieved in four patients, $\mathrm{CC}-1$ in three and $\mathrm{CC}-2$ in one patient.

\section{Pharmacokinetics}

Perfusate and blood ultrafiltrate concentrations from the patients are given in Fig. 1. The elimination half-lives in the perfusate and the percentage of dose absorbed are given in Table 2. The mean half-life was $29.5 \mathrm{~min}$ and the mean absorbed amount was $48.4 \%$. The amount absorbed was corrected for chemical degradation in the perfusate during the perfusion $(5-10 \%)$. The ratio of the found initial concentration of oxaliplatin in the perfusate and the expected concentration taking into account the dose and volume of perfusate was 0.9 . The ratio $\mathrm{C}_{\max }$ perfusate/ $\mathrm{C}_{\max }$ blood ultrafiltrate was 28.4 and the ratio of AUC perfusate

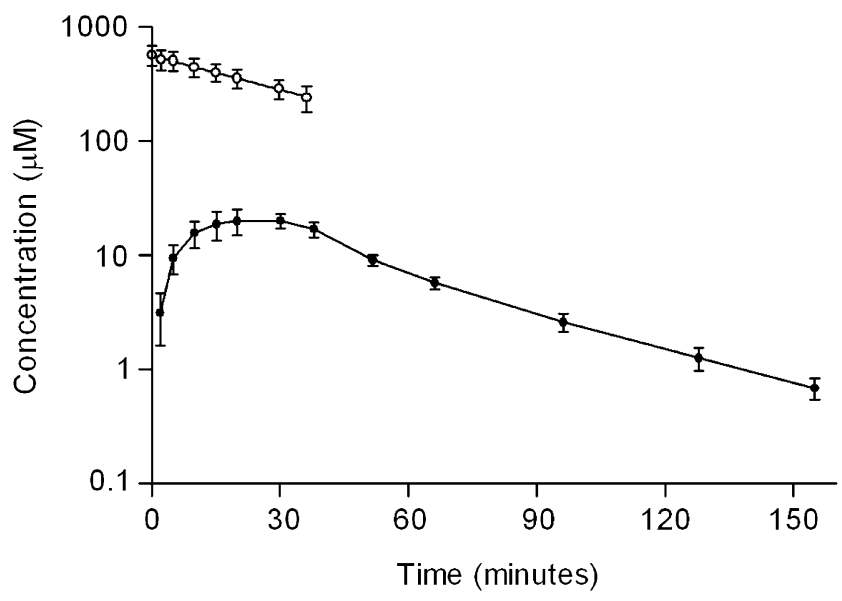

Fig. 1 Perfusate (open circles) and blood ultrafiltrate (filled circles) concentrations following administration of oxaliplatin 


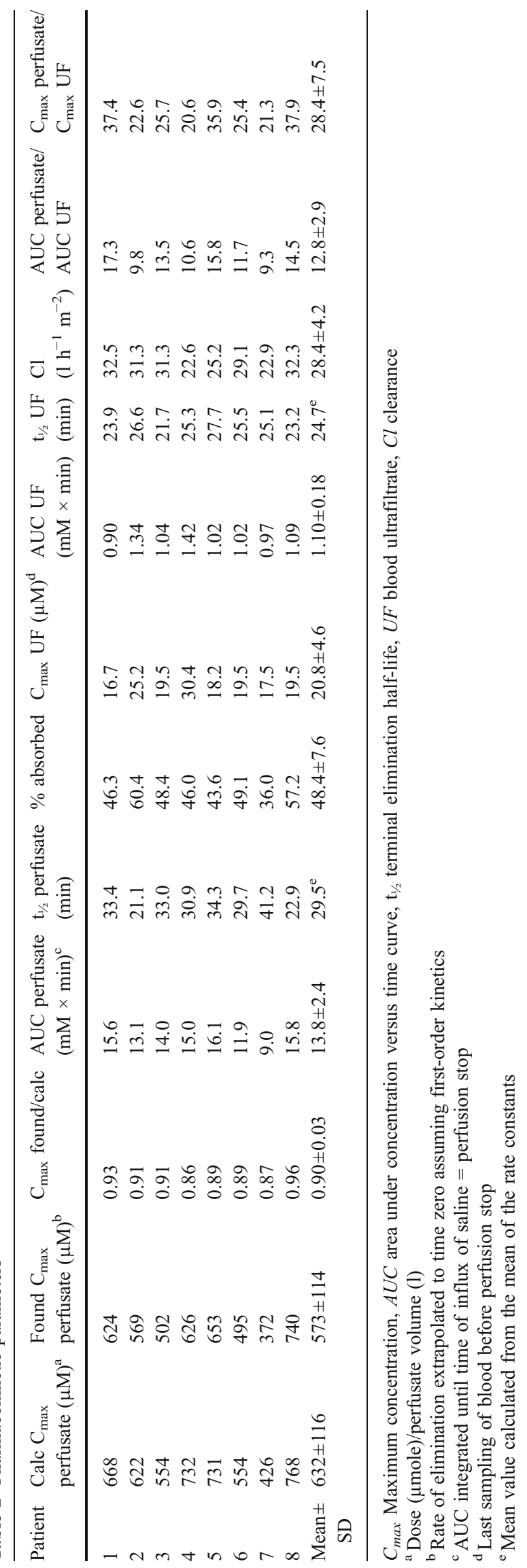

to AUC blood ultrafiltrate was 12.8 (Table 2). There was a positive correlation $(P=0.028)$ between the BMI of the patients and the percentage of oxaliplatin absorbed (Fig. 2).

The mean elimination half-life in the peripheral circulation was $24.7 \mathrm{~min}$, and the total body clearance $28.4 \mathrm{l} \mathrm{h}^{-1} \mathrm{~m}^{-2}$.

\section{Discussion}

The pharmacokinetics of oxaliplatin during HIPEC has so far only been studied using the unselective analytical technique of AAS measuring the total platinum content $[6,7]$. Since oxaliplatin rapidly reacts with endogenous sulphur compounds [16] forming a variety of reaction products, AAS will overestimate the concentration of the active drug. The present paper gives an evaluation of the kinetics of oxaliplatin during HIPEC using a selective analytical technique measuring only the parent drug [8] and comparing the results with previous data after iv administration using the same technique [11].

The ratio of the intraperitoneal and systemic exposure was 12.8 showing a local regional advantage of the drug in this setting. The elimination of oxaliplatin from the peritoneal compartment involves absorption to the general circulation, reaction with solid tissues in the peritoneum [6] and chemical degradation in the perfusate solution. The rate of degradation varied among the patients $(5-10 \%)$ as established by the in vitro studies, most probably due to differing amounts of red blood cells in the perfusate (cf. [9]). The mean elimination half-life in the perfusate and the percent dose absorbed were in general agreement with previous results $[6,7]$, which is to be expected since the major Pt-containing agent in the perfusate is intact oxaliplatin. Patients with higher BMI showed increased absorption of oxaliplatin, which might be due to a larger peritoneum surface area.

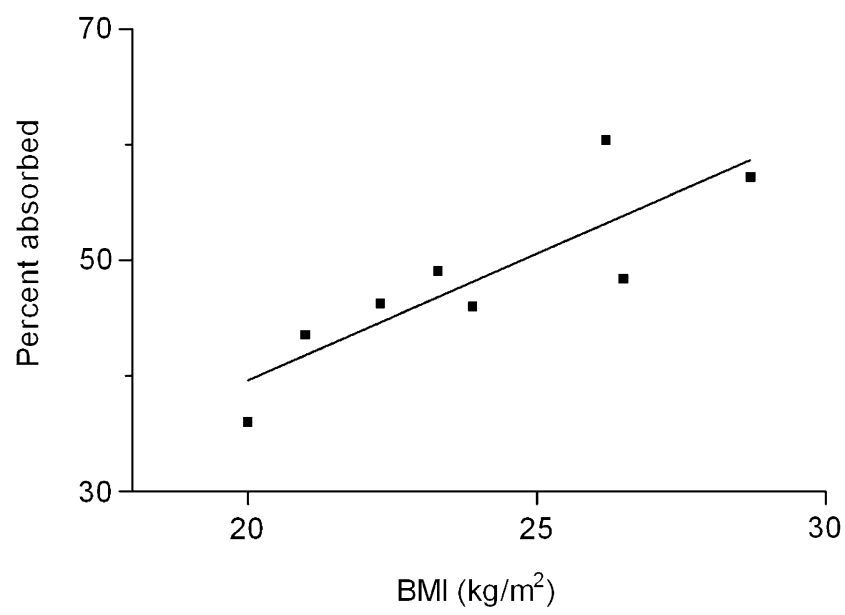

Fig. 2 Correlation between the percentage of oxaliplatin absorbed and body mass index 
The systemic exposure of oxaliplatin was about four times lower than previously reported in studies analysing ultrafiltrated platinum by using AAS [6, 7]. This is due to the fact that, with time, intact oxaliplatin will constitute a gradually decreasing fraction of total ultrafiltrated Pt due to its high chemical reactivity with endogenous compounds [16].

The blood ultrafiltrate AUC after HIPEC was about two times higher than our previous data showed after iv administration of $130 \mathrm{mg} / \mathrm{m}^{2}$ over $30 \mathrm{~min}$ [11]. The blood elimination half-life was longer $(P=0.0002)$ and the total body clearance shorter $(P=0.0047)$ than previous results after iv administration [11]. The reason for this is not quite clear but prolonged half-life and decreased clearance have been reported during anaesthesia and have been attributed to decreased hepatic flow and/or decreased glomerular filtration rate [17].

Acknowledgements The authors gratefully acknowledge the expert work of RN Ida Abrahamsson and RN Caroline Riesenfeld with sampling material. The study was supported by grants (ALF) from University Hospital, Uppsala, Sweden.

Open Access This article is distributed under the terms of the Creative Commons Attribution Noncommercial License which permits any noncommercial use, distribution, and reproduction in any medium, provided the original author(s) and source are credited.

\section{References}

1. Mahteme H, Påhlman L, Glimelius B, Graf W (1996) Prognosis after surgery in patients with incurable rectal cancer: a populationbased study. Br J Surg 83:1116-1120

2. Shepherd NA, Baxter KJ, Love SB (1997) The prognostic importance of peritoneal involvement in colonic cancer: a prospective evaluation. Gastroenterology 112:1096-1102

3. Assersohn L, Norman A, Cunningham D et al (1999) Influence of metastatic site as an additional predictor for response and outcome in advanced colorectal carcinoma. Br J Cancer 79:1800-1805

4. Elias D, Blot F, El Otmany A et al (2001) Curative treatment of peritoneal carcinomatosis arising from colorectal cancer by complete resection and intraperitoneal chemotherapy. Cancer 92:71-76

5. van Leeuwen BL, Graf W, Påhlman L, Mahteme H (2008) Swedish experience with peritonectomy and HIPEC. HIPEC in peritoneal carcinomatosis. Ann Surg Oncol 15:745-753

6. Elias D, Bonnay M, Puizillou JM et al (2002) Heated intraoperative intraperitoneal oxaliplatin after complete resection of peritoneal carcinomatosis: pharmacokinetics and tissue distribution. Ann Oncol 13:267-272

7. Ferron G, Dattez S, Gladieff L et al (2008) Pharmacokinetics of heated intraperitoneal oxaliplatin. Cancer Chemother Pharmacol (in press)

8. Ehrsson H, Wallin I (2003) Liquid chromatographic determination of oxaliplatin in blood using post-column derivatization in a microwave field followed by photometric detection. J Chromatogr B 795:291-294

9. Ehrsson H, Wallin I, Yachnin J (2002) Pharmacokinetics of oxaliplatin in humans. Med Oncol 19:261-265

10. Guthoff I, Lotspeich E, Fester C et al (2003) Hepatic artery infusion using oxaliplatin in combination with 5-fluorouracil, folinic acid and mitomycin C: oxaliplatin pharmacokinetics and feasibility. Anticancer Res 23:5203-5208

11. Pfeiffer P, Sørbye H, Ehrsson H et al (2006) Short-time infusion of oxaliplatin in combination with capecitabine $\left(\mathrm{XELOX}_{30}\right)$ as second-line therapy in patients with advanced colorectal cancer after failure to irinotecan and 5-fluorouracil. Ann Oncol 17:252258

12. Graham MA, Lockwood GF, Greenslade D et al (2000) Clinical pharmacokinetics of oxaliplatin: a critical review. Clin Cancer Res 6:1205-1218

13. Sugarbaker PH, Jacquet P, Stephens AD et al (1996) Comparison of covered versus closed technique for heated intraoperative intraperitoneal chemotherapy for peritoneal carcinomatosis from gastrointestinal cancer. In: Abe O, Inokuchi K, Takasaki K (eds) XXX World Congress of the International College of Surgeons. Monduzzi Editore, Bologna, pp 389-393

14. Sugarbaker PH (2003) Peritonectomy procedures. Surg Oncol Clin N Am 12:703-727

15. Harmon RL, Sugarbaker PH (2005) Prognostic indicators in peritoneal carcinomatosis from gastrointestinal cancer. Int Semin Surg Oncol 2:3-13

16. Jerremalm E, Wallin I, Yachnin J, Ehrsson H (2006) Oxaliplatin degradation in the presence of important biological sulphurcontaining compounds and plasma ultrafiltrate. Eur J Pharm Sci 28:278-283

17. Fushan X, Baihua S, Qin Z, Laikui L (1996) Effects of enflurane and isoflurane anesthesia on the pharmacokinetics of pancuronium in adult patients. Chin Med J 109:233-237 